\title{
Application of Game Theoretical Model for Water Management in Rajkot City, Gujarat, India
}

\author{
Reema Gupta ${ }^{1^{*}}$, B. K. Singh ${ }^{2}$, Gaurav Agarwal $^{3}$ \\ ${ }^{1}$ Department of Mathematics, IFTM University, Moradabad, U.P, India \\ ${ }^{2}$ Department of Mathematics, IFTM University, Moradabad, U.P, India \\ ${ }^{3}$ Department of Civil Engineering, SOE, RK University, Rajkot, Gujarat, India \\ *Corresponding Author: reemaagarwal142@gmail.com
}

Available online at: www.isroset.org

Accepted 22/Aug/2018, Online 30/Aug/2018

\begin{abstract}
Water is essential for the existence of society and needs in all human activities. In the present study, a game theoretical model developed to encourage the maximization of the public benefits in water distribution management in Rajkot city for different players. The present study concludes that Rajkot city demand-supply gap is 33 MLD and is expected to increase to 119 MLD and 236 MLD by 2035 and 2050 respectively. By 2035, when the population of Rajkot city grows to 21 lakh, the present water capacity would be insufficient to provide almost $50 \%$ of the city. This gap is continually increasing day by day as population increases and will become double in the year 2050. In the present study, five user game-theoretical model formulated for five players (industry, public, institutional, domestic and UFW) to minimize water demand supply gap based on current water supply in Rajkot city from all five water sources i.e. Ajii-I, Narmada, Nyari-I, Bhadar, Nyari-II. Asymmetric Nash bargaining approach is used to develop a game-theoretic model for the optimization of the weighted Nash product to obtain the actual solutions. From the study, it concluded that there is no water distribution strategy which satisfies the need of domestic users with current water distribution system. It calls for the establishment of new sources of water supply, their conservation, and optimal utilization.
\end{abstract}

Keywords - Water demand-supply gap, Water management, Game theory, Game theoretic model

\section{INTRODUCTION}

Water is essential for the existence of society and needs in all human activities. Access to safe freshwater now regarded as a worldwide human right (United Nations Committee on Economic, Social and Cultural Rights, 2003) [1]. It predicted that by 2025 , one-third of the inhabitants of the developing world would face severe water shortages [2]. The availability of safe drinking fresh water is essential, and probably it will become critically insufficient due to the increasing demand for water, the continuous quick urban population growth, and expansion of agriculture and industrial actions. As populations are continuously growing so, user water demands will also be increasing [3]. Water resources are very under pressure from all over the world, particularly in drier countries, and this condition becomes worst because of climate change [4]. It has predicted that more than 2 billion people are affected by water shortages currently in over forty countries among which 1.1 billion people do not have adequate fresh drinking water [5]. There is enough water on earth, but it is distributed unevenly, polluted, unsustainably managed and wasted too much[6]. Growing consumption of water by aggressive water demands has resulted in severe water conflicts and succeeding ecological crisis. In the present study, a game theoretical model developed to encourage the maximization of the public benefits in water distribution management in Rajkot city for different players.

\section{LITERATURE REVIEW}

Game theory has applied to water resource management problems during the past decade. Becker and Easter (1995) used game theory to analyze the interdependency among eight states and two provinces concerning water diversions from the Great Lakes [7]. Carraro and Madani reviewed that the applicability of Game Theory in water resources management through a series of non-cooperative water resource games. Some cooperative game theoretic solutions (i.e., the core, Nash-Harsanyi, Shapley, and nucleolus) were formulated and applied by Madani and Dinar, through a numerical groundwater example. J.C Harsanyi developed an equilibrium solution for an n-person bargaining problem based on an initial Nash equilibrium solution for the twoperson game [8]. Karamouz et al. used Nash product for the formulation of the objective function of a reservoir water 
allocation model and used resiliency and vulnerability indices to evaluate the performance of optimization algorithms [9]. Shouke Wei and Albrecht Gnauck (2007) explained that the water reservoirs management is complicated, and involved with multi-users. Water conflicts usually arise between multi-users due to their water use. They developed game theoretic models for water quality management of Danjiangkou Reservoir in Hanjiang River Basin in China as a game and used non-cooperative game theory results in a prisoner's dilemma and exacerbates the deterioration of water quality [10]. Madani, Kaveh (2010) reported that managing water resources systems usually involves conflicts in water resource management and game theory can identify and interpret such conflicts related to water resource problems. Outcomes predicted by game theory often differ from results suggested by optimization methods which assume all parties were willing to act towards the best system-wide outcome and reviewed the applicability of game theory in water resources management and conflict resolution throughout a series of non-cooperative water resource games[11]. Najmeh Mahjouri and Mojtaba Ardestani (2010) developed a new game theoretic optimization model to the competing users in water donor and receiving basins based on their water demands. For different coalitions of water users, the water shares of the coalitions determined by using an optimization model with economic objectives regarding the physical and environmental constraints of the system. Some cooperative game theoretic approaches utilized for transfer management to economic, equity, and environmental criteria, in a largescale inter-basin water allocation problem in Iran [12]. Wang Zhanping and Tian Juncang (2012) discussed and analyzed the water resource demand of every area in different periods by economic development planning and possible development of super-normal conditions for Yinchuan City. The optimal water resource distribution model had established with optimization theory [13]. Ahmadi Ardeshir (2013) introduced the water distribution problem of the Mexican Valley and modeled as a three-person noncooperative Game in which agriculture, industry, and domestic water users are the players and the total water Amounts supplied to the users were the payoff functions. A nonlinear optimization problem derived based on the KuhnTucker necessary Conditions [14].

\section{STUDY AREA}

Rajkot city's primary water sources are surface water sources located near around the city. City's population as per 2011 is 1.2 million. As Rajkot city recognized as a developed town, so the future population estimation is done based on arithmetical increase method considering 30 years design period and 03 years time lag between design and completion of the project based on Manual on Water Supply \& Treatment, published by Central Public Health and Environmental Engineering Organization (CPHEEO).

Table-1 Population Forecasting of Rajkot City

\begin{tabular}{|c|c|c|c|}
\hline S. N & Year & Description & Population \\
\hline 1 & 2001 & Census Department & 1003015 \\
\hline 2 & 2011 & Census Department & 1323363 \\
\hline 3 & 2017 & Design Year & 1515572 \\
\hline 4 & 2020 & Base Year & 1688560 \\
\hline 5 & 2035 & Middle of Design Period & 2092198 \\
\hline 6 & 2050 & End of Design Period & 2572720 \\
\hline
\end{tabular}

In the present study, the projection for coming 30 years was considered to compares city's population with the water demand after every 15 years.

Table-2 Total Water Demand of Rajkot City

\begin{tabular}{|l|l|l|l|l|}
\hline \multirow{2}{*}{\multicolumn{1}{|c|}{ Need of Water }} & \multicolumn{4}{|c|}{ Water Demand (MLD) } \\
\cline { 2 - 5 } & \multicolumn{4}{|c|}{ Year } \\
\cline { 2 - 5 } & $\mathbf{2 0 1 7}$ & $\mathbf{2 0 2 0}$ & $\mathbf{2 0 3 5}$ & $\mathbf{2 0 5 0}$ \\
\hline Domestic Demand & 176 & 196 & 243 & 321 \\
\hline Institutional @ 7\% & 12.31 & 13.71 & 16.99 & 22.45 \\
\hline Industrial @ 20\% & 35.16 & 39.17 & 48.54 & 64.15 \\
\hline Public Use @ 3\% & 5.27 & 5.88 & 7.28 & 9.62 \\
\hline UFW @28\% to 20\% & 49.23 & 39.17 & 48.54 & 64.15 \\
\hline Total Demand & 278 & 294 & 364 & 481 \\
\hline
\end{tabular}

Rajkot Municipal Corporation (RMC) is daily withdrawing 245 MLD water from various surface water sources. The present water demand for the Rajkot City is 278 MLD. The present study concludes that the population of Rajkot city by 2035 would inhabit by over 21 lakh and would need about 364 MLD water and in further 15 years, that is by 2050 the population would reach 26 lakh and would need about 481 MLD water. Rajkot city demand-supply gap is 33 MLD and is expected to increase to 119 MLD and 236 MLD by 2035 and 2050 respectively. By 2035, when the population of Rajkot city grows to 21 lakh, the present water capacity would be insufficient to provide almost $50 \%$ of the city. This gap is continually increasing day by day as population increases and will become double in the year 2050.

Table-3 Water Demand Supply Gap of Rajkot

\begin{tabular}{|c|c|c|c|c|}
\hline \multirow{2}{*}{$\begin{array}{c}\text { Water Demand Supply } \\
\text { Gap (MLD) }\end{array}$} & \multicolumn{4}{|c|}{ Year } \\
\cline { 2 - 5 } & $\mathbf{2 0 1 7}$ & $\mathbf{2 0 2 0}$ & $\mathbf{2 0 3 5}$ & $\mathbf{2 0 5 0}$ \\
\hline Water Demand & 278 & 294 & 364 & 481 \\
\hline Water Supply & 245 & 245 & 245 & 245 \\
\hline Demand Supply Gap & 33 & 49 & 119 & 236 \\
\hline
\end{tabular}

\section{MODEL FORMULATION}

Game theory is a mathematical construction for analyzing the strategies of each decision maker or player to maximize each player's possibility of winning and to forecast possible outcomes of the game. Mathematically, five different users 
are competing for the water; those are Industrial $(\mathrm{k}=1)$, Unaccounted $(\mathrm{k}=2)$, Institutional $(\mathrm{k}=3)$, domestic $(\mathrm{k}=4)$ and Public $(\mathrm{k}=5)$. The common objective of all the users is to minimize water deficiency or to maximize water supply. However, there are limited freshwater sources in the city which results in a disagreement between these users. Let, index of the users is $\mathrm{k}=1,2,3,4,5$, for each of them the decision variables are:

\section{Ajii-I $\left(a_{k}\right)$}

2. Narmada $\left(n_{k}\right)$

3. Nyari-I $\left(n y_{k}\right)$

4. Bhadar $\left(b_{k}^{*}\right)$

5. Nyari-II $\left(n y_{k}^{*}\right)$

Here every water user, i.e., Industrial, Unaccounted for Water (UFW), Institutional, Domestic and Public wants to maximize its water supply i.e.

$$
\max a_{k}+n_{k}+n y_{k}+b_{k}^{*}+n y_{k}^{*}
$$

There are two general limitations for each user. Water supply cannot exceed the k user's water demand Dk. Each user required a minimum amount of water as $D_{k}^{\min }$. The users have two common constraints. The complete water quantity cannot go beyond the demand:

$$
a_{k}+n_{k}+b_{k}^{*}+n y_{k}+n y_{k}^{*} \leq D_{k}
$$

Each user need a minimum amount of water as

$$
a_{k}+n_{k}+b_{k}^{*}+n y_{k}+n y_{k}^{*} \geq D_{k}^{\min }
$$

In addition to these constraints, each user has its conditions. Industrial users $(\mathrm{k}=1)$ have two particular constraints. Let $A_{N}$ Minimum quantity of Narmada water that is used by industry and $A_{N y}$ Maximum quantity of Nyari-I water that is used by industry.

$$
\frac{n_{1}+n y_{1}^{*}}{a_{1}+n_{1}+n y_{1}+b_{1}^{*}+n y_{1}^{*}} \geq A_{N}
$$

It can write as

$$
A_{N} a_{1}+\left(A_{N}-1\right) n_{1}+A_{N} n y_{1}+A_{N} b_{1}^{*}+\left(A_{N}-1\right) n y_{1}^{*} \leq 0
$$

And

$$
\frac{n y_{1}}{a_{1}+n_{1}+n y_{1}+b_{1}^{*}+n y_{1}^{*}} \leq A_{N y}
$$

It can write as:

$$
-A_{N y} a_{1}-A_{N y} n_{1}+\left(1-A_{N y}\right) n y_{1}-A_{N y} b_{1}^{*}-A_{N y} n y_{1}^{*} \leq 0
$$

Unaccounted for water (UAF) users $(\mathrm{k}=2)$ have one additional constraint. Let $A_{u}$ Maximum proportion of Nyari-
I's water that can use for the unaccounted purpose and can write as follows:

$$
\frac{n y_{2}}{a_{2}+n_{2}+n y_{2}+b_{2}^{*}+n y_{2}^{*}} \leq A_{u}
$$

It can write as:

$$
-A_{u} a_{2}-A_{u} n_{2}+\left(1-A_{u}\right) n y_{2}-A_{u} b_{2}^{*}-A_{u} n y_{2}^{*} \leq 0
$$

Institutional users $(\mathrm{k}=3)$ have one additional constraint is used. Let AI , the maximum proportion of the Narmada and Nyari-I water that can use for institutional purpose. It can

$$
\text { write as: } \frac{n_{3}+n y_{3}}{a_{3}+n_{3}+n y_{3}+b_{3}^{*}+n y_{3}^{*}} \geq A_{I}
$$

It can write as:

$$
A_{I} a_{3}+\left(A_{I}-1\right) n_{3}+A_{I} n y_{3}^{*}+A_{I} b_{3}^{*}+\left(A_{I}-1\right) n y_{3} \leq 0
$$

Domestic users $(\mathrm{k}=4)$ have one additional constraint is used. Let $A_{d}$, the maximum proportion of Nyari-I's water that can use for domestic purpose and can write as:

$$
\frac{n y_{4}}{a_{4}+n_{4}+n y_{4}+b_{4}^{*}+n y_{4}^{*}} \leq A_{d}
$$

It can write as:

$$
-A_{d} a_{4}-A_{d} n_{4}+\left(1-A_{d}\right) n y_{4}-A_{d} b_{4}^{*}-A_{d} n y_{4}^{*} \leq 0
$$

Public users $(\mathrm{k}=5)$ have one additional constraint is used. Let $A_{P}$, the maximum proportion of Nyari-I's water that can use for public purpose and can write as follows:

$$
\frac{n y_{5}}{a_{5}+n_{5}+n y_{5}+b_{5}^{*}+n y_{5}^{*}} \leq A_{P}
$$

It can write as:

$$
-A_{p} a_{5}-A_{P} n_{5}+\left(1-A_{P}\right) n y_{5}-A_{P} b_{5}^{*}-A_{P} n y_{5}^{*} \leq 0
$$

The additional constraints can represent the total water availability of all sources:

$$
\begin{gathered}
a_{1}+a_{2}+a_{3}+a_{4}+a_{5}=S_{a} \\
n_{1}+n_{2}+n_{3}+n_{4}+n_{5}=S_{n} \\
n y_{1}+n y_{2}+n y_{3}+n y_{4}+n y_{5}=S_{n y} \\
b_{1}^{*}+b_{2}^{*}+b_{3}^{*}+b_{4}^{*}+b_{5}^{*} \leq S_{b^{*}} \\
n y_{1}^{*}+n y_{2}^{*}+n y_{3}^{*}+n y_{4}^{*}+n y_{5}^{*} \leq S_{n y^{*}}
\end{gathered}
$$


As it stated previously, each user wants to minimize its water deficiency which is equivalent to maximize the total quantity of water supply.

$$
\operatorname{Max} a_{k}+n_{k}+b_{k}^{*}+n y_{k}+n y_{k}^{*} \quad(k=1,2,3,4,5)
$$

This problem can consider as a five-person game, in which the water users are the players, the strategy of player $\mathrm{k}$ is the decision vector. If $p=\left(p_{1}, p_{2}, p_{3}, p_{4}, p_{5}\right)$ is the simultaneous strategy vector of the three players, then it has to satisfy conditions. The below equation give the payoff function of user. Observe that all constraints and payoff functions are linear. Hence the dilemma can be rewritten in the form of the matrix as follows:

$$
\begin{array}{cl}
\text { Maximum } & z_{k}^{T} p_{k} \quad(k=1,2,3,4,5) \\
\text { sub to } & p \geq 0 \\
& X p \leq y
\end{array}
$$

Where, $z_{k}^{T}=(1,1,1,1,1)$ and the elements of vector $\mathrm{y}$ and matrix $\mathrm{X}$ are resolved by the constraints. Also, we require that

$$
w_{1}+w_{2}+w_{3}+w_{4}+w_{5}=1
$$

Then the non-symmetric Nash bargaining solution can be obtained as the optimal solution of the following nonlinear optimization problem.

$$
\begin{gathered}
\max \quad\left(z_{k}^{T} p_{1}-D_{1}^{\min }\right)^{w_{1}}\left(z_{k}^{T} p_{2}-D_{2}^{\min }\right)^{w_{2}}\left(z_{k}^{T} p_{3}-D_{3}^{\min }\right)^{w_{3}} \\
\left(z_{k}^{T} p_{4}-D_{4}^{\min }\right)^{w_{4}}\left(z_{k}^{T} p_{5}-D_{5}^{\min }\right)^{w_{5}} \\
\text { sub to } \quad p \geq 0 \\
X p \leq y
\end{gathered}
$$

All the users treated in the same manner which is supposed by the symmetry axiom, but it is not possible if the users have different factors. The Nash bargaining approach is a method for utility distribution. In the present study, the asymmetric Nash bargaining approach is used to satisfy all other axioms. An optimal distribution of additional benefits can obtain through the Nash bargaining game. There are two assumptions was used to allocate water to the different users. First, it is a game of complete information. It means that all the information for each user treated as ordinary knowledge; such as water demand and benefit functions. Second, differences exist over the bargaining power of players, and the differences will affect the player's share. Therefore, the asymmetric Nash bargaining approach utilized in analyzing this game.

\section{RESULT ANALYSIS}

In the result analysis, Rajkot city water demand data used for the analysis of water distribution. The current water distribution shows that total water distribution from the first source Aji-I river is 6.612 MLD for domestic need, 1.656 MLD for institutional need, 10.447 MLD for industrial need, 7.815 MLD for unaccounted for waste, and 0.920 MLD for public demand. From the second source Narmada, the distribution is 99.922 MLD for domestic need, 6.010 MLD for institutional need, 11.005 MLD for industrial need, 8.683 MLD for unaccounted for waste, and 3.380 MLD for public demand. Bhadar river water is distributed 46 MLD for domestic need only. From Nyari-I total 11.412 MLD water is distributed for domestic purpose, 1.769 MLD water for the institutional purpose, 10.696 MLD water for industrial need, 7.129 MLD water waste unaccountably and 0.994 MLD water distributed for public use. From Nyari-II water is distributed for domestic purpose only. It means that the total available water in Nyari-I is $32\left(=\mathrm{S}_{\mathrm{ny}}\right)$ MLD, Nyari-II is 11 MLD $\left(=\mathrm{S}_{\mathrm{ny}}\right)$, Ajii-I is $27 \mathrm{MLD}\left(=\mathrm{S}_{\mathrm{a}}\right)$, Bhadar is $46 \mathrm{MLD}$ $\left(=\mathrm{S}_{\mathrm{b}^{*}}\right)$ and Narmada canal is $129 \operatorname{MLD}\left(=\mathrm{S}_{\mathrm{n}}\right)$.

The total water demand for the industrial user is 35MLD $\left(=\mathrm{D}_{1}\right)$, the Unaccounted user is $49.00 \operatorname{MLD}\left(=\mathrm{D}_{2}\right)$, Institutional use is $12.31 \mathrm{MLD}\left(=\mathrm{D}_{3}\right)$, Domestic user is174.496 MLD $\left(=\mathrm{D}_{4}\right)$, and the Public user is 5.00 MLD $\left(=\mathrm{D}_{5}\right)$. However, minimum water demand for the industrial user is $32.148 \operatorname{MLD}\left(=D_{1}^{\min }\right)$, the institutional user is 9.420 $\operatorname{MLD}\left(=D_{3}^{\min }\right)$, the domestic user is 90.00 MLD $\left(=D_{4}^{\min }\right)$, the public user is $0.050 \operatorname{MLD}\left(=D_{5}^{\min }\right)$, unaccounted demand is 23.627 MLD. $\left(=D_{2}^{\min }\right)$. The water supply in industry from Narmada is $34 \%$ and from Nyari-I it is $33 \%$. Total Water supply to institutional demand is from Narmada and Nyari - I is $83 \%$. Domestic water demand from Nyari-1 is $6.5 \%$ only.

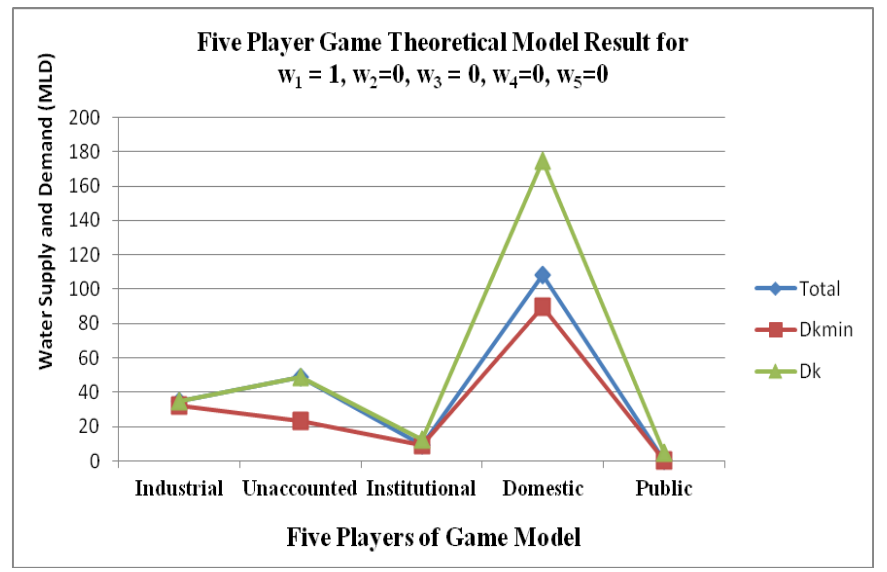

Figure 1. Five Player game Model Result for $\mathrm{w}_{1}=1, \mathrm{w}_{2}=0, \mathrm{w}_{3}=0, \mathrm{w}_{4}=0, \mathrm{w}_{5}=0$ 


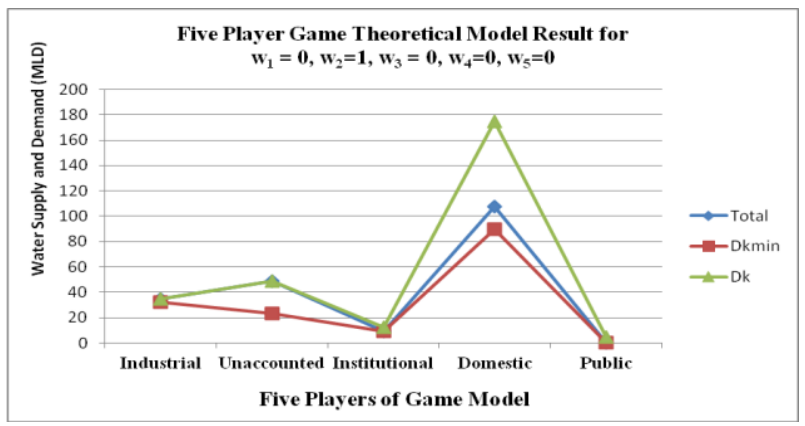

Figure 2. Five Player game Model Result for $\mathrm{w}_{1}=0, \mathrm{w}_{2}=1, \mathrm{w}_{3}=0, \mathrm{w}_{4}=0, \mathrm{w}_{5}=0$

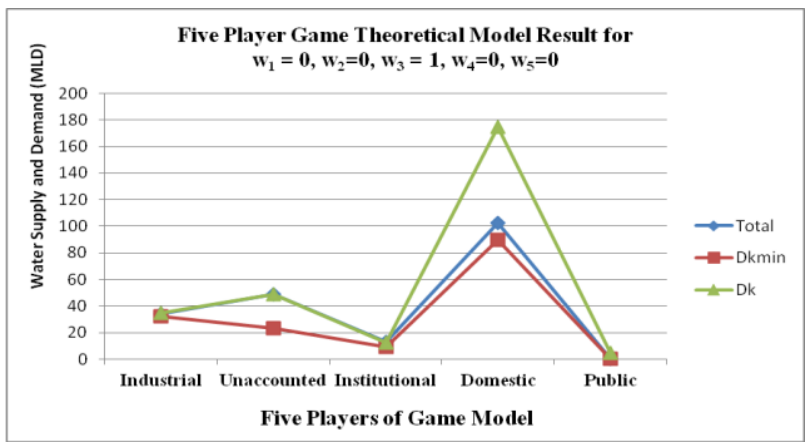

Figure 3. Five Player game Model Result for $\mathrm{w}_{1}=0, \mathrm{w}_{2}=0, \mathrm{w}_{3}=1, \mathrm{w}_{4}=0, \mathrm{w}_{5}=0$

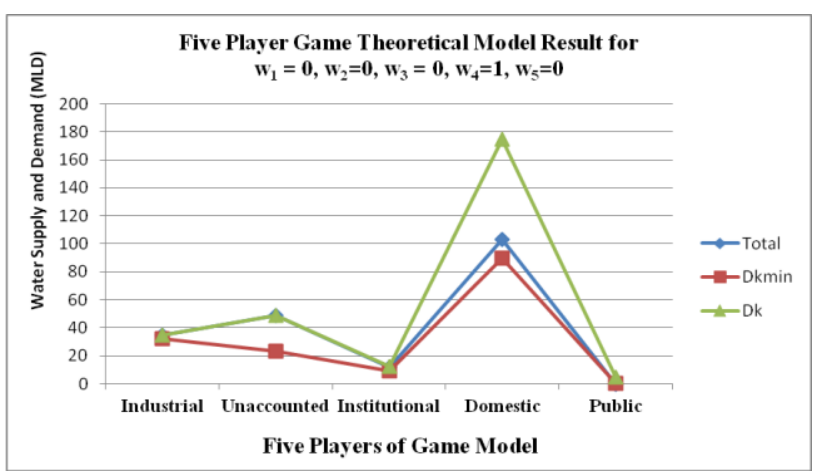

Figure 4. Five Player game Model Result for $\mathrm{w}_{1}=0, \mathrm{w}_{2}=0, \mathrm{w}_{3}=0, \mathrm{w}_{4}=1, \mathrm{w}_{5}=0$

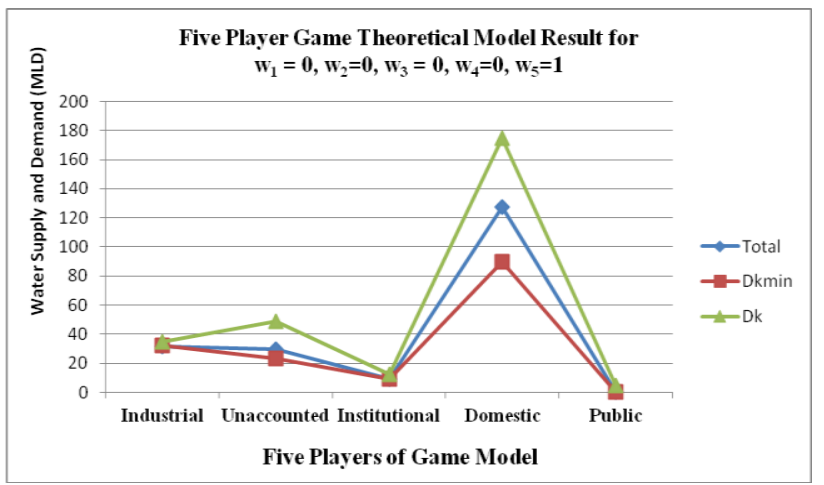

Figure 5. Five Player game Model Result for $\mathrm{w}_{1}=0, \mathrm{w}_{2}=0, \mathrm{w}_{3}=0, \mathrm{w}_{4}=0, \mathrm{w}_{5}=1$
On comparing the five users' game theoretical model results in Figure-6, it shows that some users cannot fulfill their total water demand, but they can fulfill their minimum water demand.

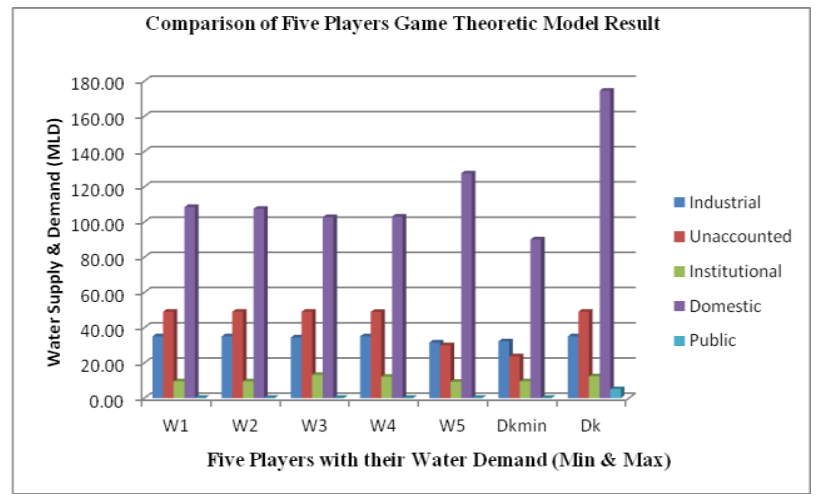

Figure 6. Comparison of Five Player Game Theoretical Model Results

\section{CONCLUSION}

In the present study, five users game-theoretic model developed based on the present water demand-supply of the Rajkot city from five water resources to minimize water demand-supply gap. In this study, water demand for design period 30 years is also estimated based on the population forecasting of Rajkot city for the years 2035 and 2050. After getting current water demand and supply, water supplydemand gap identified for the study area. It concludes that the present water demand for the Rajkot City is 278 MLD considering per capita water demand of $135 \mathrm{lpcd}$ and $40 \mathrm{lpcd}$ for stand post while water supply is 245 MLD. The demandsupply gap is continually increasing day by day as population increases. Present water demand supply gap is 33 MLD for Rajkot city and is expected to increase to 119 MLD and 236 MLD by 2035 and 2050 respectively. By 2035, when the population of Rajkot city grows to 21 lakh, the present water supply would be insufficient to provide almost $50 \%$ of the city and expected to almost double by 2050 .

In the study, five users game-theoretic model formulated for five players (Industry, public, institutional, domestic and Unaccounted for Water) using five water resources (Ajii-I, Narmada, Nyari-I, Bhadar, Nyari-II). RMC is providing freshwater to all five users and competing with each other in maximizing their freshwater supply. In the study, asymmetric Nash bargaining approach is used to develop a game-theoretic model for the optimization of the weighted Nash product to obtain the actual solutions. From the study, it concluded that there is no water distribution strategy which satisfies the need of domestic users with current water distribution system. It calls for the establishment of new sources of water supply, their conservation, and optimal utilization.

\section{REFERENCES}

[1] L. J. M. Zbigniew and W. Kundzewicz, "Freshwater resources 
and their management," World Water, pp. 173-210, 2007.

[2] A. Keller, R. Sakthivadivel, and D. Seckler, "Water scarcity and the role of storage in development," Water Manag., Vol. 39, pp. 124, 2000.

[3] Central Water Commission, "Reassessment of Water Resources Potential of India," 1999.

[4] A. Georgakakos et al., "Climate change impacts in the United States," Third Natl. Clim. ..., pp. 69-112, 2014.

[5] Harinarayan Tiwari, N. Sharma, A. Khan, and S. P. Rai, "Water Resources in India: A view from third eye," in India Water Week 4-8 April 2016: "Water for All- Striving Together" Water, 2016, pp. 1-13.

[6] A. McIntosh and J. Pontius, "Global Water Resources," Case Stud. Integr. Sci. Glob. Environ., pp. 113-254, 2017.

[7] R. Supalla, B. Klaus, O. Yeboah, and R. Bruins, "A game theory approach to deciding who will supply instream flow water," J. Am. Water Resour. Assoc., vol. 38, no. 4, pp. 959-966, 2002.

[8] M. Homayounfar, M. Zomorodian, C. J. Martinez, and S. H. Lai, "Two Monthly Continuous Dynamic Model Based on Nash Bargaining Theory for Conflict Resolution in Reservoir System," PLoS One, vol. 10, no. 12, p. e0143198, 2015.

[9] M. Karamouz, M. Akhbari, A. Moridi, and R. Kerachian, "A system dynamics-based conflict resolution model for river water quality management," J. Environ. Heal. Sci. Eng., vol. 3, no. 3, pp. 147-160, 2006.

[10] S. Wei and A. Gnauck, "Game theory based water quality models for reservoir management," Proc. EnviroInfo Warsaw 2007 Environ. Informatics Syst. Res. Vol. 1 Plenary Sess. Pap. Warsaw Pol., pp. 363-370, 2007.

[11] K. Madani, "Game theory and water resources," J. Hydrol., vol. 381, no. 3-4, pp. 225-238, 2010.

[12] N. Mahjouri and M. Ardestani, "A game theoretic approach for interbasin water resources allocation considering the water quality issues," Environ. Monit. Assess., vol. 167, no. 1-4, pp. 527-544, 2010.

[13] W. Zhanping and T. Juncang, "Optimal Allocation of Regional Water Resources Based on Genetic Algorithms," J. Converg. Inf. Technol., vol. 7, no. 13, pp. 437-445, 2012.

[14] A. Ahmadi, "Water Distribution as a no Cooperative Game," vol. 13, no. 3, 2013.

\section{AUTHORS PROFILE}

Mrs. Reema Gupta pursed M.Sc., Mathematics from MJP Rohilkhand University, U.P, India in 2004. She is currently working as Lecturer in Department of Humanities and Science from SLTIET, Rajkot, Gujarat, India since 2013. Her main research work focuses on application of game theory in water resource management and planning. She has 11 years of teaching experience and 07 years of research experience. 